\title{
Study on Product Sensory Quality Assurance System Based on PLM
}

\author{
Jingwen $\mathrm{An}^{1,}$,, Miao Wang ${ }^{1, \mathrm{~b}}$ \\ School of Management, China University of Mining and Technology, Beijing, China \\ aemail, bemail,
}

Keywords: Sensory Quality; PLM; Assurance System

\begin{abstract}
Sensory quality is an important product feature. It can affect consumer judgment and behavior. We put forward a kind of sensory quality assurance system with the concept PLM theory, to improve the enterprise management status of sensory quality.
\end{abstract}

\section{Introduction}

Sensory quality refers to the sensory perception of product features, this feature include the consumer experience of the five senses (touch, sight, taste, smell and hearing) and affect c onsumer perception, judgment and behavior.Product sensory quality make corresponding prod uct quality in view of the "five senses", to make every consumer who contact the product can feel the product differentiation, and has a more comprehensive and profound perception of the product. Sensory quality management is not only a kind of advanced quality manag ement strategy, but also a kind of fine a marketing strategy. Krishna who have engaged in sensory study for 20 years published monograph Custom Sense: How the 5 Senses Influenc e Buying Behavior(2013), which reviewed the main research achievements in the field of se nsory quality, and puts forward a series of management advice for enterprise management $\mathrm{p}$ ersonnel[1]. Krishna think enterprise should implement sensory makeover strategy, the well-k nown brand should be imprint sensory signature in the minds of consumers.

\section{Product Sensory Quality Assurance System based on PLM}

Guiding Principles. In this paper, the product sensory quality assurance system framework is based on the customer requirements, and take product sensory quality management process as the goal, and take the guiding principles of multi-level, multi-view and multi-method.

Multi-level including demand layer, function layer, question layer and tool layer.Demand layer disintegrate customer demand, which can expressthecustomer's needs more clearly. Function layer determine the content of quality activities and their functions. Question layer confirm process failure causes,the frequency and severity in the sensory quality process. Tools layer provides tools for sensory quality management of the product life cycle. 
Multi-view Refersto modeling sensory quality assurance system from the perspective of pro duct life cycle, process organization and quality activities. PLM usually be divided into five stages of customer demand stage, quality planning stage. Process organization perspective in cludes plan management, resource management and product management, sensory quality ass urance system model implement process activities support by configuration process model. Q uality activities perspective is specific activities to ensure the sensory quality of products and meet user requirements .

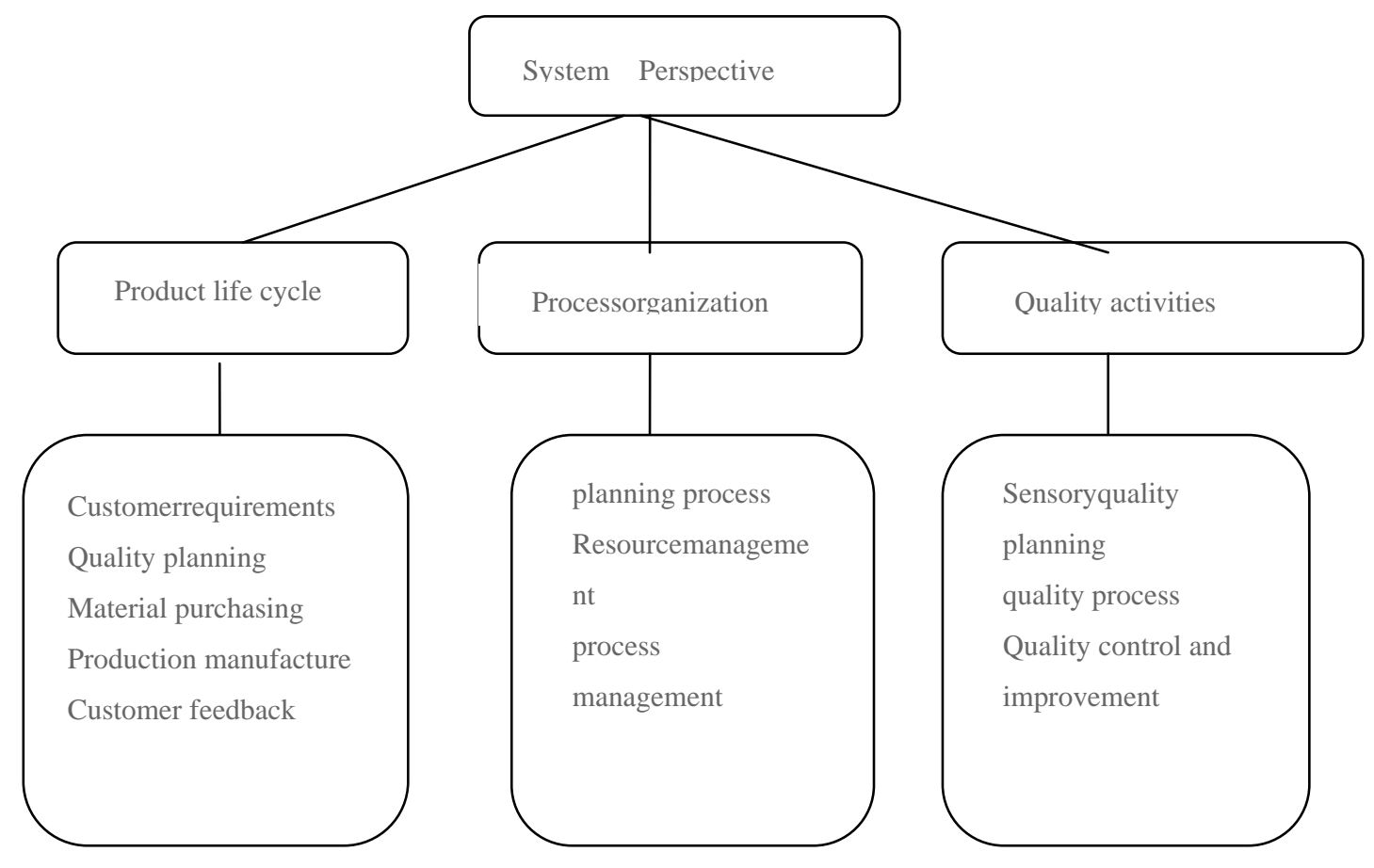

Figure1.Sensory Quality Assurance System View

Multi-method conclude QFD, FMEA, 4M1E and SPC. QFD is used to transfer customer $\mathrm{r}$ equirements to the technical attributes.FMEA and 5M1E are used to decompose the sensory quality system process and identify the failure mode.SPC is taken to implement and improve process.

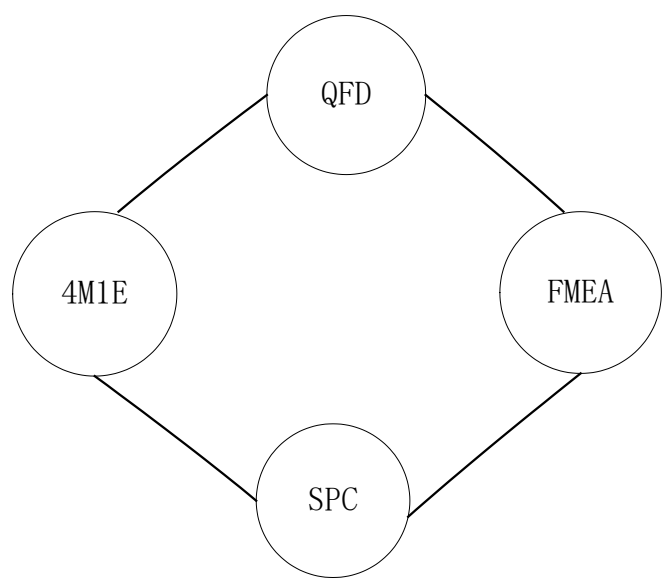

Figure2. Sensory Quality Guarantee SystemMethods

Implementation Process. Implementation sensory quality assurance system need to follow the standardized process management,take the continued improve as goal, consider all the po ssible problems of every step,and use the appropriate tools and methods for unified planning [2]. The following table shows the general implementation steps. 
Table 1. System Implementation Process

\begin{tabular}{|c|c|c|c|}
\hline Implementation steps & Step content & Involved problem & $\begin{array}{l}\text { Using } \\
\text { methods }\end{array}$ \\
\hline $\begin{array}{l}\text { Sensory quality } \\
\text { planning }\end{array}$ & $\begin{array}{l}\text { Identify the customer demand } \\
\text { for products of sensory qualit } \\
\text { y, determine the sensory requir } \\
\text { ements and technical attributes } \\
\text { mapping relationship }\end{array}$ & $\begin{array}{l}\text { what is the sensory quality? } \\
\text { what is Sensory } \\
\text { quality technical properties? } \\
\text { The } \\
\text { relationship betweenrequirement } \\
\text { s and technical attributes }\end{array}$ & $\begin{array}{l}\text { AHP } \\
\text { RoughSet } \\
\text { ANP } \\
\text { QFD } \\
\text { KANO }\end{array}$ \\
\hline $\begin{array}{l}\text { Process identification } \\
\text { Factors identification } \\
\text { Failureomde confirmati } \\
\text { on }\end{array}$ & $\begin{array}{l}\text { Determine formation of sensory } \\
\text { quality, identify the influence } \\
\text { factors, determine the process } \\
\text { failure model }\end{array}$ & $\begin{array}{l}\text { What is the overall process of } \\
\text { the process, how can we } \\
\text { describe? } \\
\text { What is the influence factors } \\
\text { of process? } \\
\text { what is the Process failure } \\
\text { mode? }\end{array}$ & $\begin{array}{l}\text { 5M1E } \\
\text { FMEA } \\
\text { Fishbone } \\
\text { Diagram } \\
\text { Causality } \\
\text { Diagram }\end{array}$ \\
\hline $\begin{array}{l}\text { Process monitoring } \\
\text { Process improvement }\end{array}$ & $\begin{array}{l}\text { Determine needed principles and } \\
\text { methods for process effective } \\
\text { operation } \\
\text { Take necessary measures }\end{array}$ & $\begin{array}{l}\text { what is the standard or } \\
\text { method of monitoring } \\
\text { procedure?How can we } \\
\text { incorporate the methods into } \\
\text { process? } \\
\text { What method is used for } \\
\text { process improvement? }\end{array}$ & $\begin{array}{l}\text { QFD } \\
\text { SPC } \\
\text { Brainstorming } \\
\text { AHP/ANP } \\
\text { Expert } \\
\text { Experience }\end{array}$ \\
\hline
\end{tabular}

System Framework. Based on the content and characteristic analysis of sensory quality management in product life cycle,this paper proposes a model of the sensory quality guarantee system as figure3 shown. The system architecture is mainly divided into the sensory quality target layer,function configuration layer ,question layer and method layer.

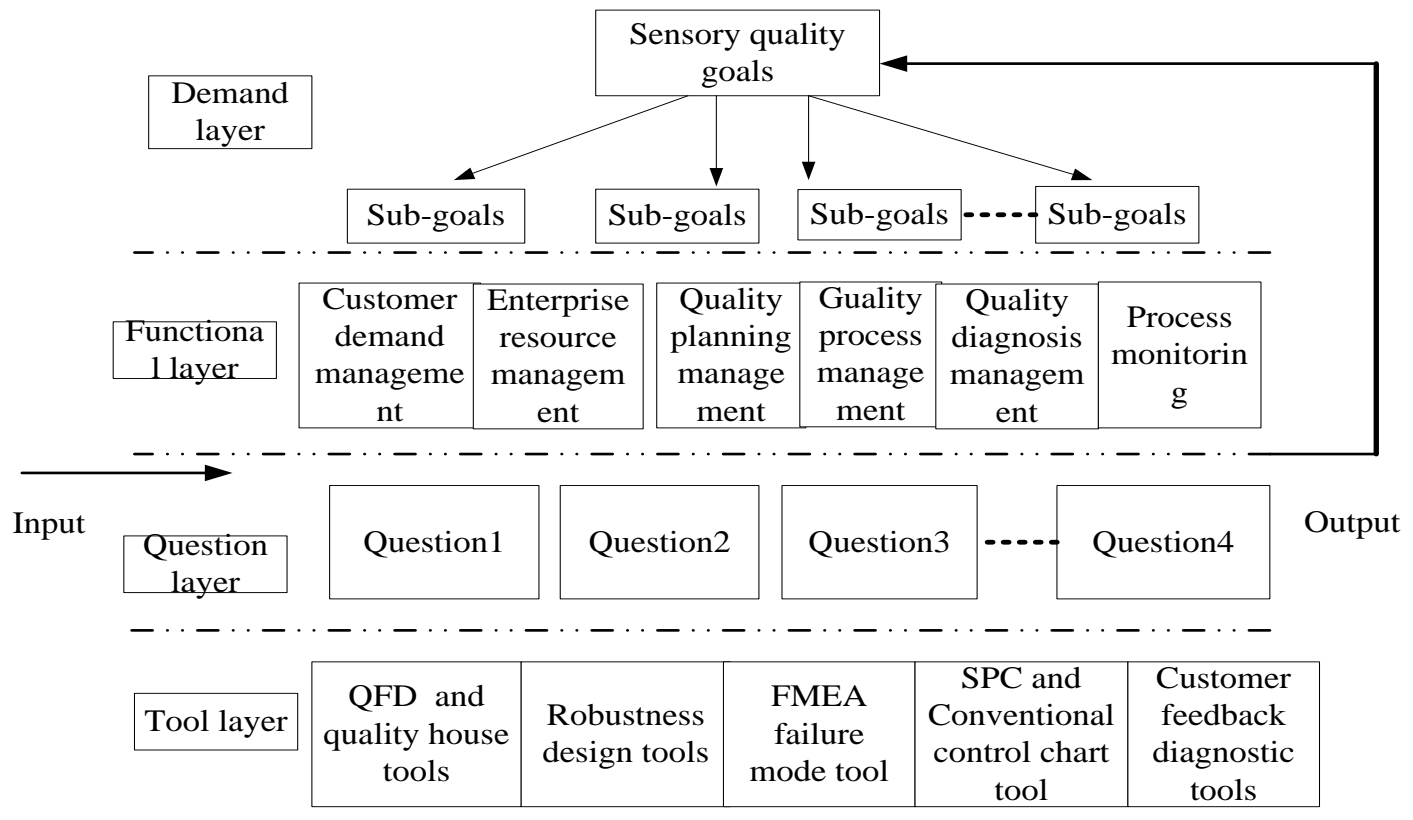

Figure3. Product Sensory Quality Assurance System Based on PLM 
(1)Sensory Quality Target Layer. The goal of sensory quality assurance system is the syste $\mathrm{m}$ input and the description of the final state ,and is also a main line and the standard of $\mathrm{q}$ uality management. Target can be disintegrate into specific executable sub-goalsaccording to the different sensory attributes.

(2) Function Configuration Layer. The sensory quality management system are formed by a series of quality management process and quality activities to fulfill quality tasksas shown in figure4 [3].The planning includes whole enterprise quality strategic planning , also contain specific plan for each quality process. Implement the planning content by the process manag ement and control ,especially the key quality management tasks in the process execution. At the same time, pay attention to the feedback of process execution, or revised process plan ning, or improve management means.

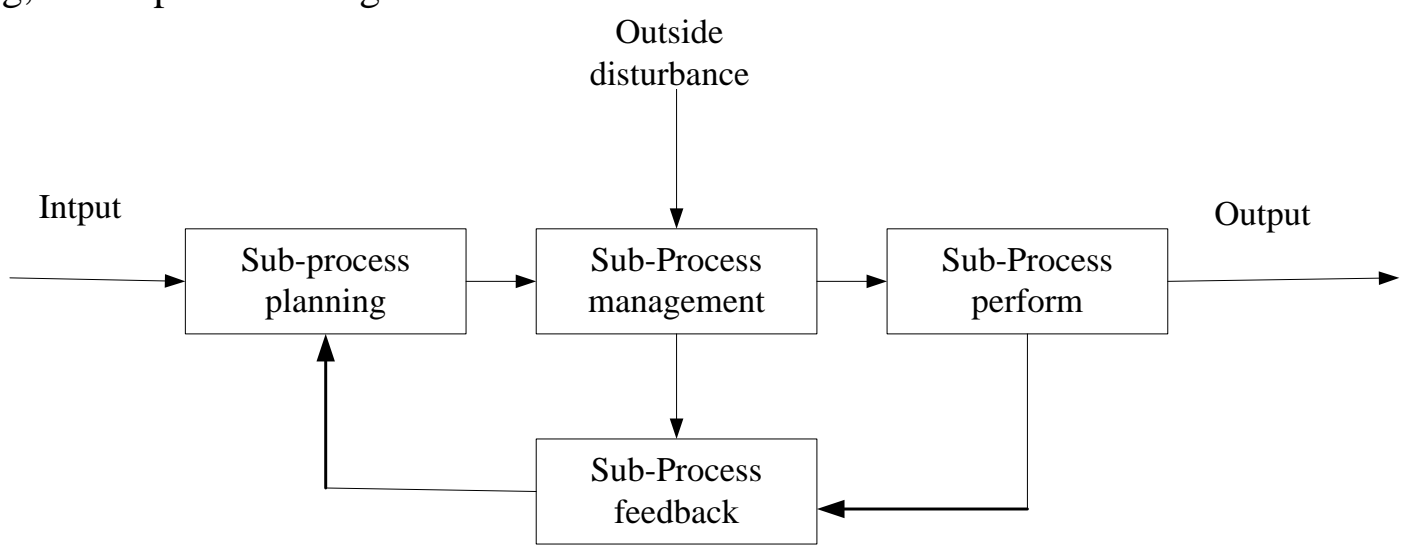

Figure4. Quality Function Deployment Flow Chart

(3) Question Layer. Question layer identify the failure points of the product sensory quality process,as well as the frequency and consequences of the failure point, which is also the $g$ oal and direction of sensory quality assurance system.

(4) Method Layer. Method layer provides tool set facing the sensory quality managemen t of the product life cycle.The tool set mainly includes QFD, 4M1E,FMEA, SPC, fuzzy AH $P$ etc[4].

\section{Conclusion}

Reasonable and advanced quality assurance system is an important foundation for the smoot $\mathrm{h}$ implementation and control sensory quality of the product life cycle management. In this paper, we put forward the process quality management ideology taking the product life cycle as the core,and on this basis, put forward the enterprise sensory quality assurance system o $\mathrm{f}$ the product life cycle.

\section{References}

[1] Zhong Ke,Wang Haizhong,and Yang Chen, "Sensory Marketing Research Review and Prospect,” Foreign Economic and Management,2016,PP.69-81.

[2] Yang Jiping, "Process quality management model and auxiliary software system development and application” , Zhe Jiang University, 2014.

[3] Wang Chen, Study on Quality Management Key Techniques of Large Passenger Aircraft Collaborative Development Process, Shang Hai University,2013.

[4] Yue Tongyun.Customer Demand Information System Research based on Mass Customization, Dalian University of Technology,2004 
[5] Li Dapeng,Guo Jianchao,Li Peng,and Zhu Dengwei, Research on R\&d project management platform based on PLM, Chinese management informationization,2016,PP.67-71

[6] Zhu Haiping,Yang Fuming,He Jie, and He Fei, key technology research and system implementation of Machine assembly quality management, Aviation manufacturing technology,2015,pp.26-30. 